\title{
High-entropy $\mathrm{Al}_{0.3} \mathrm{CoCrFeNi}$ alloy fibers with high tensile strength and ductility at ambient and cryogenic temperature
}

\author{
DongyueLi ${ }^{\mathrm{a}}$, ChengxinLi ${ }^{\mathrm{a}}$, Tao Feng ${ }^{\mathrm{b}}$, Yidong Zhang ${ }^{\mathrm{b}}$, Gang Sha $^{\mathrm{b}}$, \\ John J. Lewandowski ${ }^{\mathrm{c}}$, Peter K. Liaw ${ }^{\mathrm{d}}$, Yong Zhang ${ }^{\mathrm{a}}$
}

${ }^{\mathrm{a}}$ State Key Laboratory for Advanced Metals and Materials, University of Science and Technology Beijing, Beijing 100083, China

${ }^{\mathrm{b}}$ Herbert Gleiter Institute of Nanoscience, Nanjing University of Science and Technology, Nanjing, Nanjing 210094, China

${ }^{\mathrm{c}}$ Case Western Reserve University, Department of Materials Science and Engineering, Cleveland, USA

${ }^{\mathrm{d}}$ Department of Materials Science and Engineering, The University of Tennessee, Knoxville, TN 37996, USA

\begin{abstract}
High-entropy alloys (HEAs) are multi-component systems based on novel alloy composition designs with entropy maximization. They feature an array of unique mechanical properties when compared with traditional alloys. In this study, HEA fibers with diameters ranging from $1-3.15 \mathrm{~mm}$ in diameter, with the composition of $\mathrm{Al}_{0.3} \mathrm{CoCrFeNi}$ (atomic percent, at. \%), were successfully fabricated by hot-drawing, followed by microstructural characterization using scanning-electron microscopy (SEM) and transmission-electron microscopy (TEM). The compositional variations within and between fibers were determined using energy-dispersive X-ray spectroscopy in TEM along with atomic-probe tomography (APT). These analyses revealed a homogeneous face-centered cubic (FCC) structure in the as-cast material, while post processing (e.g., forging and wire drawing) produced nanosized B2


particles in an FCC matrix. Electron back-scatter diffraction (EBSD) was used to determine the evolution of the texture and grain boundary character after processing of the fibers. The tensile strength and plasticity of the fibers were determined at both 298K $(1,207 \mathrm{MPa} / 7.8 \%)$ and $77 \mathrm{~K}(1,600 \mathrm{MPa} / 17.5 \%)$. Detailed TEM analyses revealed that the improvement of mechanical properties at $77 \mathrm{~K}$ (i.e. increased strength and ductility) is due to a change in deformation mechanism from the planar slip of dislocations to nano-twinning. Such properties could be beneficial for cryogenic applications.

Key words: high-entropy alloy; fibers; tensile strength and ductility; cryogenic behavior; nano-twinning

\section{Introduction}

High entropy alloys (HEAs) ${ }^{[1-12]}$ represent a breakthrough from traditional alloy-design concepts where only one or two dominant elements comprise the base components since HEAs contain at least five major metal elements in equal or near equal-atomic ratios. These alloys also typically favor the formation of simple and disordered solid-solution structures, such as face-centered-cubic (FCC), body-centered cubic $(\mathrm{BCC})$, or hexagonal close-packed structures $(\mathrm{HCP})^{[3,13-\text { Error! }}$ Bookmark not defined.]. In addition to a high mixed entropy that follows Boltzmann's hypothesis regarding the relationship between entropy and alloy system complexity, these structural characteristics are ascribed to the large lattice distortion and sluggish diffusion in such multiple-element mixtures ${ }^{[1,3,12-13]}$. This novel alloy-design concept 
has developed into a new field in metallurgy where the focus for alloy design has moved away from the corners of alloy-phase diagrams toward their centers, resulting in unique microstructures and promising properties ${ }^{[11-12]}$. Recent studies have shown that HEAs exhibit great thermal stability, great fatigue, wear and corrosion resistance, and increased hardness in comparison to conventional alloys, as well as outstanding elevated and cryogenic temperature properties ${ }^{[3-}$ Error! Bookmark not defined. ${ }^{30]}$. These characteristics qualify HEAs as potential candidates to meet demanding requirements for selected extreme applications, particularly in the nuclear, turbine, and aerospace industries $^{[3,12,31-32]}$.

Over the last decade, significant efforts have been devoted to advancing the understanding of the microstructures and properties of HEAs in the as-cast condition. Casting defects, such as the casting porosity, composition segregation, and inhomogeneous microstructures are promoted by the sluggish diffusion characteristic in HEAs ${ }^{[33]}$. While there is an expectation to break this intrinsic process for casting HEAs, conventional thermal post processing techniques (e.g., forging, hot drawing, hot isostatic pressing, etc.) to reduce/eliminate such defects have been recently investigated. These techniques also permit high-throughput mass production of near-net-shape profiles with good surface finish. Moreover, forging and hot-drawing methods are associated with large compressive hydrostatic stresses, which delay brittle failure and, thus, facilitate the accumulation of high plastic strains ${ }^{[34]}$ and beneficial changes in texture ${ }^{[35-37]}$. As such, it may be possible to optimize mechanical properties by these thermo-mechanical treatments and by investigating the texture 
evolution and deformation mechanisms that operate under different processing conditions $^{[13,38-39]}$.

The $\mathrm{Al}_{\mathrm{x}} \mathrm{CoCrFeNi}$ alloy system ${ }^{[40]}$ studied presently was identified several years ago and shown to transition from single $\mathrm{FCC}$ to $\mathrm{BCC}$ phases with increasing $\mathrm{Al}$ content ${ }^{[33,41-42]}$. While both the hardness and strength increased with an increase in the volume fraction of the $\mathrm{BCC}$ phase, the alloy also became brittle. The $\mathrm{Al}_{0.3} \mathrm{CoCrFeNi}$ alloy was chosen for this investigation since it has a single-phase FCC structure and balanced properties (e.g., strength, ductility, and toughness ${ }^{[29-30]}$. Furthermore, others have shown that tailored properties can be achieved with suitable heat treatments ${ }^{[43]}$.

In this study, $\mathrm{Al}_{0.3} \mathrm{CoCrFeNi}$ quinary alloy fibers were successfully fabricated into fibers with diameters of 1.00 to $3.15 \mathrm{~mm}$ using traditional deformation processing techniques. The microstructure of the HEA fibers was systematically studied, followed by extensive tensile testing and subsequent examination of structure evolution after deformation to identify deformation and fracture mechanisms.

\section{Experiments}

Alloy ingots with a nominal composition of $\mathrm{Al}_{0.3} \mathrm{CoCrFeNi}$ (atomic percent, at. \%) were fabricated by vacuum-levitation, melting a mixture of pure metals (purity > 99 wt. \%, weight percent) in a high-purity argon atmosphere. The ingots were re-melted at least three times in order to ensure chemical homogeneity, followed by hot forging and hot rotary swaging into $6 \mathrm{~mm}$ rods at $1,050{ }^{\circ} \mathrm{C}$ and $1,000{ }^{\circ} \mathrm{C}$, respectively. Finally, HEA fibers with diameters of 1.00 to $3.15 \mathrm{~mm}$ were produced by hot-drawing at $900{ }^{\circ} \mathrm{C}$. 
Phase formation in the longitudinal sections of the fibers was determined by X-ray diffraction (XRD) on a Huber-2 goniometer ( $\mathrm{Cu}-\alpha$ radiation), followed by microstructure characterization using scanning-electron microscopy (SEM) with a Zeiss Supra55operated at $20 \mathrm{keV}$, along with energy-dispersive spectrometry (EDS). The chemical homogeneity within a grain was examined using local electrode atom-probe tomography ${ }^{[10,44-49]}$ (APT) (LEAP 4000X SI) under a high vacuum of approximately $2.5 \times 10^{-11}$ torr, at the temperature of $25 \mathrm{~K}$, a target evaporation rate of $1 \%$, and a pulsing ultraviolet laser energy of 50 pJ. A sharp APT tip was prepared, using two-stage electro-polishing of a $1.00 \mathrm{~mm}$ diameter HEA wire. The first stage electropolishing was performed using an electrolyte containing 25 volume percent(vol.\%) perchloric acid in acetic acid at $15 \mathrm{~V}$ and room temperature, and the second stage was by a 2 vol.\% perchloric acid in 2-butoxyethanol solution at $20 \mathrm{~V}$.

Considering the relatively low accuracy of X-ray diffraction (XRD) for precipitate detection, phase identification in this study was also conducted by the neutron diffraction, high-resolution transmission electron microscopy (TEM) with a JEM-2010. The TEM samples were made by two-step polishing methods. The TEM samples were first mechanically ground to a thickness of $40 \mu \mathrm{m}$, then twin-jet electro-polished with a solution of $\mathrm{HNO}_{3}: \mathrm{CH}_{4} \mathrm{O}=1: 4$. The grains in the fibers were analyzed using electron backscatter diffraction (EBSD), and their texture was represented by inverse pole figures (IPFs) corresponding to the fibers axis (deformation direction).

Tensile tests at strain rates of $1 \times 10^{-3} \mathrm{~s}^{-1}, 2 \times 10^{-4} \mathrm{~s}^{-1}$, and $5 \times 10^{-5} \mathrm{~s}^{-1}$ at $298 \mathrm{~K}$, 
and at a strain rate of $2 \times 10^{-4} \mathrm{~s}^{-1}$ at $77 \mathrm{~K}$ were carried out on the fibers, using a CMT4105 universal electronic-tensile testing machine with a sample gauge length of $15 \mathrm{~mm}$. The hardness of the fibers was measured, using a Vickers hardness tester with a load of $500 \mathrm{~g}$, held for $15 \mathrm{~s}$. For each specimen, at least 12 hardness tests were measured in order to obtain adequate statistics.

\section{Results}

\subsection{Phase formation and microstructure}

Figure 1 shows a photograph of the continuous fibers with diameters of 1.00 to $3.15 \mathrm{~mm}$. The fibers were cylindrically-shaped and almost flawless, which implied that the hot-drawing method is an effective technique for the production of high-quality HEA fibers. The X-ray diffraction patterns of the $\mathrm{Al}_{0.3} \mathrm{CoCrFeNi}$ alloys undergoing various processing techniques are shown in Fig. 2. The main phase, a single FCC crystal structure, was identified. While the smaller diameter fibers maintained a predominant FCC structure, new peaks appeared at $20^{\circ}$ to $30^{\circ}$.

SEM images are presented in Figs. $3 a$ to $3 c$, which exhibit the wire surface morphologies with the diameters of $3.15,1.60$, and $1.00 \mathrm{~mm}$, respectively. Fine-scaled precipitation was observed in the fibers shown in the energy-dispersive spectroscopy (EDS) of $1.00 \mathrm{~mm}$ diameter HEA fibers in Fig. 3d. TEM and chemical analyses identified that these particles were NiAl-rich precipitates, Fig. 4, consistent with the minor XRD peaks that evolve in the finer-diameter fibers in Fig. 2. Figure 3e shows the distribution of the alloying elements ( $\mathrm{Al}, \mathrm{Co}, \mathrm{Cr}, \mathrm{Fe}$, and $\mathrm{Ni})$ in the matrix of the $1.00 \mathrm{~mm}$ diameter HEA fibers determined by APT. The composition of the 
fibers appeared to be relatively uniform in the atom maps for the regions analyzed.

The TEM investigation, Fig. 4, indicated that the fibers were composed of a (Co, $\mathrm{Cr}$, and Fe)-rich matrix, and a NiAl-type ordered BCC (e.g., B2) phase. The selected area electron diffraction (SAED) patterns confirmed the coexistence of the FCC matrix and B2 secondary phase, while the electron energy dispersive spectroscopy (EDS) analysis revealed that this secondary phase contained more $\mathrm{Al}$ and $\mathrm{Ni}$ than in the matrix. The chemical composition (at. \%) in the matrix and particles of the fibers are listed in Table 1. A similar NiAl-rich B2 phase was reported in other Al-containing HEA systems ${ }^{[50,51]}$, while the B2 phase was found to be stronger and more brittle than that of the FCC matrix. This trend is considered to be reasonable, as the mixing enthalpy of $\mathrm{Ni}$ and $\mathrm{Al}$ is significantly negatively lower than that of the other atom pairs of the five principal elements. As is known, the thermodynamic equilibrium equation is as shown:

$$
\Delta \mathrm{G}_{\mathrm{mix}}=\Delta \mathrm{H}_{\mathrm{mix}}-\mathrm{T} \Delta \mathrm{S}_{\mathrm{mix}}
$$

where $\Delta \mathrm{G}_{\mathrm{mix}}$ is the mixing of the Gibbs-free energy; $\Delta \mathrm{H}_{\text {mix }}$ is the mixing of the enthalpy; $\Delta \mathrm{S}_{\mathrm{mix}}$ is the mixing of the entropy; and $\mathrm{T}$ is the absolute temperature. According to Equation [1], a phase with the larger negative mixing enthalpy has a lower Gibbs-free energy. However, the peaks of the B2 phase were absent from the X-ray diffraction spectra, presumably resulting from the limited volume fraction (e.g., $5 \%$ ) present. Much other work has reviewed the mechanical properties of bulk NiAl-B2 type materials ${ }^{[52-53]}$. 
The TEM micrographs in Fig. 5a, 5b, and 5c show cellular structures that have evolved in the $\mathrm{Al}_{0.3} \mathrm{CoCrFeNi}$ fibers, with diameters of $3.15,1.60$ and $1.00 \mathrm{~mm}$, respectively. In this study, in order to discern the microstructure in the grain boundary and the orientation, the EBSD examination was performed on the HEA fibers, and the results are shown in Fig. 6. It can be clearly seen that most of the grain sizes of the fibers were smaller than $2 \mu \mathrm{m}$ (Figs. 6a, 6b, and 6c). When the diameters of the fibers were drawn to $1.60 \mathrm{~mm}$ (Fig. 6b), some of the grains became longer due to drawing under conditions that did not produce recrystallization. However, after repeated thermal drawings to $1.00 \mathrm{~mm}$ (Fig. 6c), the grains became equiaxed due to recrystallization. The texture of the $<100>$ and $<111>$ along the axial direction of the $\mathrm{Al}_{0.3} \mathrm{CoCrFeNi}$ alloy fibers following thermal processing was confirmed by the EBSD orientation data, as shown in Figs. 6d, 6e, and 6f. The average grain size was approximately $1.60 \mu \mathrm{m}$ in each diameter of fibers, as shown in Fig. 7.

\subsection{Mechanical properties}

The measured uniaxial stress-strain curves at room temperature $(298 \mathrm{~K})$ and in liquid nitrogen $(77 \mathrm{~K})$ are plotted in Figs. $8 \mathrm{a}, 8 \mathrm{~b}$, and 8c, respectively. The $1.00 \mathrm{~mm}$ diameter fibers were additionally tested at both $298 \mathrm{~K}$ and $77 \mathrm{~K}$ at a strain rate of $2 \mathrm{x}$ $10^{-4} \mathrm{~s}^{-1}$. The yield strength $\left(\sigma_{\mathrm{y}}\right)$ and ultimate tensile strength $\left(\sigma_{\mathrm{uts}}\right)$ increased, respectively, from 1,136 to $1,320 \mathrm{MPa}$ and from 1,207 to $1,600 \mathrm{MPa}$ on going from $298 \mathrm{~K}$ to $77 \mathrm{~K}$, while the tensile ductility also increased from $7.8 \%$ to $17.5 \%$. It was found that the Vickers hardness, as illustrated in Fig. 8f, achieved more than $300 \mathrm{HV}$ in the drawn fibers, significantly higher than that of as-cast or single-crystal 
samples $^{[26,54]}$. Figure 9a shows extensive necking in one of the drawn fibers. The difference in elongation shown in Table 2 indicates the significant post-necking strain exhibited by all of the fibers tested in this study. The fracture-surface morphology from samples tested at $298 \mathrm{~K}$ is shown in Figs. 9b, 9c, and 9d, while Figs. 9e, 9f, and $9 \mathrm{~g}$ show fracture morphologies of samples tested at $77 \mathrm{~K}$. All samples exhibited ductile fracture morphologies and micro-void coalescence (MVC), consistent with the high ductility as shown in Table 2 .

Figures 10a and 10b show the TEM micrographs and deformation substructures of the $3.15 \mathrm{~mm}$ diameter fibers after tension testing at a strain rate of $2 \times 10^{-4} \mathrm{~s}^{-1}$ at 298 and 77 K, respectively. For the current alloy system, the dislocation density of the fibers after tensile testing was significantly enhanced (Fig. 10a), compared to that present before the tensile test (Fig. 5a). The multiple interactions between the dislocations and fine-scaled precipitates further increased the resistance of the dislocation motion with increasing deformation, thereby leading to the significant strengthening. However, deformation-induced nanoscaled twinning at $77 \mathrm{~K}$ was also observed in the present study, as shown in Fig. 10b, likely contributing to both the increases in strength and ductility obtained at $77 \mathrm{~K}$, as discussed below.

\section{Discussion}

\subsection{Precipitate particles}

As shown in Figs. 3a, 3b, and 3c, there were massive fine particles distributed in the FCC matrix. Among the various interactions between the $\mathrm{Al}$ and 3d-transition metals analyzed by Tang ${ }^{[31]}$ using the CALPHAD (calculation of phase diagrams and 
thermochemistry) method, the B2 type Al-Ni phase was found to possess an enthalpy value of $-43 \mathrm{~kJ} / \mathrm{mol}$ at $800{ }^{\circ} \mathrm{C}$, while the enthalpies of the mixing for the $\mathrm{Cr}-\mathrm{Al}$ and Fe-Al solid solutions as the FCC structure was determined to be positive. Because of this trend, the formation of the $\mathrm{B} 2 \mathrm{Al}-\mathrm{Ni}$ phase was expected in the present $\mathrm{Al}_{0.3} \mathrm{CoCrFeNi}$ alloys, thereby requiring alloying-element partitioning between the $\mathrm{B} 2$ and $\mathrm{Al}$ phases during the thermal-deformation processing. In addition, theoretical studies using ab initio molecular dynamics simulations ${ }^{[55]}$ (AIMD) predicted preferred interatomic inter-actions of $\mathrm{Al}$ and $\mathrm{Ni}$, even in the liquid state ${ }^{[56]}$.

The dislocation motion was blocked by precipitated particles during the deformation. The critical shear stress ${ }^{[57]}$ for the dislocation can be calculated as follows:

$$
\tau=\frac{G b}{\lambda} .
$$

where $\tau$ is the critical shear stress; $G$ is the shear modulus; $b$ is the Burgers vector; and $\lambda$ is the distance between the particles. Due to the dislocation by-pass and particle shearing mechanism, the precipitates will produce hardening. As shown in Figs. 3a, 3b, and $3 \mathrm{c}$ and Figs. 4a, 4d, and 4g, there are precipitates, and these precipitates are expected to produce hardening, either through a dislocation particles shearing mechanism or by-pass mechanism (Orowan-type). Generally, shearing mechanism occurs when precipitates are sufficiently small and coherent. However, Orowan mechanism would dominate when the radius of particles exceeds a critical value or is incoherent with the matrix. Based on the incurrent precipitate morphology, particle by-pass mechanism is expected to take the control. 


\subsection{Cellular structures in the thermally-drawing fibers}

The cellular structures, shown in Figs. 5a, 5b, and 5c for the 3.15, 1.60 and 1.00 $\mathrm{mm}$ diameter fibers, respectively, were generated during the process of thermal drawing. Reducing the wire diameter increased the dislocation density and decreased the dislocation-cell size in Figs. 5a, 5b, and 5c. Similar work on drawn fibers of other materials (e.g., 1080 steel) also present the formation of cellular structures with increased wire drawing ${ }^{[58]}$.

\subsection{Relationship between microstructures and mechanical properties}

In a recent study, cold rolling and subsequent annealing treatments have been carried out to obtain grain refinement in HEAs ${ }^{[59]}$. The high tensile strength and ductility of the present $\mathrm{Al}_{0.3} \mathrm{CoCrFeNi}$ alloy fibers is associated with the microstructures that have evolved presently. In particular, the B2-type Al-Ni phase is much harder than the matrix and presents a barrier to gliding dislocations. In addition, the present $\mathrm{Al}_{0.3} \mathrm{CoCrFeNi} \mathrm{HEA}$ fibers exhibited a fine-grained microstructure with significant textures of $<111>$ and $<100>$, as shown in the EBSD images (Fig. 6) taken along the longitudinal direction of the fibers. Prior to recrystallization, it appears that each grain turned to the axial sliding direction of rotation during the drawing process, while the grain rotation eventually stabilized at the symmetrical position. In general, these factors play crucial roles in the microstructural evolution and properties during thermo-mechanical processing.

Traditionally, solid-solution hardening, grain-boundary hardening, dislocation hardening, and precipitation hardening are the main strengthening mechanisms in 
polycrystalline materials ${ }^{[60]}$. The higher strength of the three different diameter fibers, compared with that of the as-cast alloy, is attributed to the higher dislocation density and refined grain size, in addition to the fine-scaled NiAl particles. The average grain size in the fibers was approximately $1.60 \mu \mathrm{m}$. However, the high internal stresses in the as-drawn fibers produced no distinguishable work hardening during the subsequent tensile test. Further appropriate heat treatments are required to reduce the internal stresses in order to acquire adjustable mechanical properties. However, both the tensile strength and ductility improved on going from $298 \mathrm{~K}$ to $77 \mathrm{~K}$. Similar strength and ductility improvements at cryogenic temperatures have been reported by Gludovatz, et. $\mathrm{al}^{[18]}$, attributed to a transition from the planar-slip dislocation activity at room temperature to nano-twinning with decreasing the temperature. Nano-twinning in that work produced a continuously-steady strain, resulting in both hardening and limiting the damage caused by the earlier local deformation. Further exploration and analysis, such as in-situ high-resolution TEM, is required to determine the onset strain and detailed mechanisms of the plastic flow. Regardless, the fracture surfaces shown in Fig. 9 reveal a high density of dimple-like features consistent with a large amount of local deformation. The density and depth of the dimple-like features also increase with increasing the ductility of the fibers.

Consistent with the increased strength in the fibers, the hardness of the $\mathrm{Al}_{0.3} \mathrm{CoCrFeNi} \mathrm{HEA}$ fibers was higher than that of the $\mathrm{Al}_{0.3} \mathrm{CoCrFeNi}$ single crystal and as-cast bulk samples ${ }^{[26]}$. Furthermore, the hardness taken from the longitudinal sections was higher than that taken on the transverse cross-sections. Since the fibers 
have an anisotropic crystal orientation, when a crystal is loaded in a different orientation, the slip system orientation is also different, producing the variation in mechanical properties obtained for different orientations.

Table 2 also provides other data on high-entropy $\mathrm{Al}_{0.3} \mathrm{CoCrFeNi}$ alloys fabricated by various methods in order to enable a comparison of properties. The present $\mathrm{Al}_{0.3} \mathrm{CoCrFeNi}$ fibers exhibited outstanding combinations of strength and ductility, with an increase in both yield and tensile strengths at $77 \mathrm{~K}$. Although there are clearly stronger metal fibers reported in Table 2, the high-entropy $\mathrm{Al}_{0.3} \mathrm{CoCrFeNi}$ fibers deserve further exploration. A direct comparison of the tensile strength and elongation of the current HEAs is presented in Fig. 11.

\subsection{APT results and deformation behavior}

The APT results show that the elemental composition of the fibers is very uniform in the matrix. This trend, along with the Ni-Al precipitates, is consistent with the lack of serrated-flow behavior in the stress-strain curves shown in Figs. 8a, 8b and $8 \mathrm{c}$. Other work has shown that dislocations will be pinned by segregation during the mechanical deformation if the solute atoms are mobile enough to segregate to the dislocations, similar to Cottrell atmospheres in carbon steels ${ }^{[61]}$. The present work has shown that the mobile species have precipitated as Ni-Al nano-particles, which combined with the more homogeneous deformation produced by such particles reduces the tendency for such flow serrations.

\section{Conclusions}

In this study, the effects of the microstructures and mechanical behavior of $13 / 20$ 
quinary $\mathrm{Al}_{0.3} \mathrm{CoCrFeNi}$ HEA fibers were studied. The main textures of the HEA fibers, which were fabricated by hot rotary forging and hot-drawing, were $<111>$ and $<100>$ fiber textures. The strong interaction between the $\mathrm{Al}$ and $\mathrm{Ni}$ atoms produced $\mathrm{B} 2 \mathrm{Al}-\mathrm{Ni}$ particles of approximately 200 nanometers. The precipitates and fine grains both contribute to the sustained high strength and extended ductility observed in the tensile tests of HEA fibers. In particular, fibers with a diameter of $1.00 \mathrm{~mm}$ displayed remarkable tensile strength and ductility $(1,207 \mathrm{MPa}$ and $7.8 \%)$ at $298 \mathrm{~K}$, increasing to $1,600 \mathrm{MPa}$ and $17.5 \%$ at $77 \mathrm{~K}$. In contrast to the planar-slip-deformation mechanisms operating at $298 \mathrm{~K}$, deformation-induced nanoscaled twinning was exhibited after deformation at $77 \mathrm{~K}$, contributing to the increased tensile strength and ductility at 77 $\mathrm{K}$. The good combinations of strength and ductility in HEA fibers at low temperatures opens up an innovative route for the future development of high-performance HEAs as engineering materials.

\section{Acknowledgements:}

The authors would like to state their appreciation to the National High Technology Research and Development Program of China (grant no. 2009AA03Z113) and the National Science Foundation of China (grant nos. 51210105006 and 51471025), and to thank them for their financial support. The authors would also like to thank the Program for Changjiang Scholars, and the Innovative Research Team of the University.

P.K. Liaw would like to acknowledge the Department of Energy (DOE), Office of Fossil Energy, National Energy, National Energy Technology Laboratory (DE-FE-0008855 and DE-FE-0024054, and DE-FE-0011194), with Mr. V. Cedro and 
Mr. R. Dunst as program managers. P.K. Liaw thanks the support from the project of DE-FE-0011194 with the program manager, Dr. J. Mullen. P.K. Liaw very much appreciates the support of the U.S. Army Research Office project (W911NF-13-1-0438) with the program manager, Dr. D.M. Stepp. P.K. Liaw thanks the support from the National Science Foundation (DMR-1611180) with the program director, Dr. D. Farkas.

\section{References:}

[1] J.W. Yeh, S.K. Chen, S.J. Lin, J.Y. Gan, T.S. Chin, T.T. Shun, C.H. Tsau, S.Y. Chang, Nanostructured high-entropy alloys with multiple principal elements: novel alloy design concepts and outcomes, Adv. Eng. Mater. 6 (5) (2004) 299-303.

[2] B. Cantor, I. Chang, P. Knight, A. Vincent, Microstructural development in equiatomic multicomponent alloys, Mater. Sci. Eng. A 375 (2004) 213-218.

[3] Y. Zhang, T.T. Zuo, Z. Tang, M.C. Gao, K.A. Dahmen, P.K. Liaw, Z. P. Lu, Microstructures and properties of high-entropy alloys, Prog. Mater. Sci. 61 (2014) 1-93.

[4] Z.P. Lu, H. Wang, M.W. Chen, I. Baker, J.W. Yeh, C.T. Liu, T.G. Nieh, An assessment on the future development of high-entropy alloys: Summary from a recent workshop, Intermetallics 66 (2015) 67-76.

[5] M.H. Tsai, J.W. Yeh, High-entropy alloys: a critical review, Mater. Res. Lett. 2 (2014) 107-123.

[6] Y. Zhang, Y.J. Zhou, J.P. Lin, G.L. Chen, P.K. Liaw, Solid-solution phase formation rules for multi-component alloys, Adv. Eng. Mater. 10 (6) (2008) 534-538.

[7] M.A. Hemphill, T. Yuan, G.Y. Wang, J.W. Yeh, C.W. Tsai, A. Chuang, P.K. Liaw, Fatigue behavior of $\mathrm{Al}_{0.5} \mathrm{CoCrCuFeNi}$ high entropy alloys, Acta Mater. 60 (16) (2012) 5723-5734.

[8] Z. Tang, T. Yuan, C.W. Tsai, J.W. Yeh, C.D. Lundin, P.K. Liaw, Fatigue behavior of a wrought $\mathrm{Al}_{0.5} \mathrm{CoCrCuFeNi}$ two-phase high-entropy alloy, Acta Mater. 99 (2015) 247-258.

[9] M. Seifi, D.Y. Li, Y. Zhang, P.K. Liaw, J.J. Lewandowski, Fracture toughness and fatigue crack growth behavior of as-cast high-entropy alloys, JOM 67 (10) (2015) 2288-2295.

[10] L.J. Santodonato, Y. Zhang, M. Feygenson, C.M. Parish, M.C. Gao, R.J.K. Weber, J.C. Neuefeind, 
Z. Tang, P.K. Liaw, Deviation from high-entropy configurations in the atomic distributions of a multi-principal-element alloy, Nat.Commun. 6 (2015) 5964.

[11] Y. Zhang, X. Yang, P.K. Liaw, Alloy design and properties optimization of high-entropy alloys, JOM 64 (7) (2012) 830-838.

[12] M.C. Gao, J.W. Yeh, P.K. Liaw, Y. Zhang, High-entropy alloys: fundamentals and applications, Springer, (2016).

[13] S. Guo, C. Ng, J. Lu, C.T. Liu, Effect of valence electron concentration on stability of fcc or bcc phase in high entropy alloys, J. Appl. Phys. 109 (10) (2011) 103505.

[14] O.N. Senkov, S.V. Senkova, C.F. Woodward, Effect of aluminum on the microstructure and properties of two refractory high-entropy alloys, Acta Mater. 68 (2014) 214-228.

[15] Y.J. Zhou, Y. Zhang, Y.L. Wang, G.L. Chen, Microstructure and compressive properties of multicomponent $\mathrm{Al}_{\mathrm{x}}(\mathrm{TiVCrMnFeCoNiCu})_{100-\mathrm{x}}$ high-entropy alloys, Mater. Sci. Eng. A 454 (2007) $260-265$.

[16] M. Feuerbacher, M. Heidelmann, C. Thomas, Hexagonal high-entropy alloys, Mater. Res. Lett. 3 (1) (2015) 1-6.

[17] Y.J. Zhao, J.W. Qiao, S.G. Ma, M.C. Gao, H.J. Yang, M.W. Chen, Y. Zhang, A hexagonal close-packed high-entropy alloy: The effect of entropy, Mater. Design 96 (2016) 10-15.

[18] M. Laurent-Brocq, A. Akhatova, L. Perrière, S. Chebini, X. Sauvage, E. Leroy, Y. Champion, Insights into the phase diagram of the CrMnFeCoNi high entropy alloy, Acta Mater. 88 (2015) $355-365$.

[19] O.N. Senkov, S.V. Senkov, C. Woodward, D.B. Miracle, Low-density, refractory multi-principal element alloys of the $\mathrm{Cr}-\mathrm{Nb}-\mathrm{Ti}-\mathrm{V}-\mathrm{Zr}$ system: Microstructure and phase analysis, Acta Mater. 61 (5) (2013) 1545-1557.

[20] B. Gludovatz, A. Hohenwarter, D. Catoor, E.H. Chang, E.P. George, R.O. Ritchie, A fracture-resistant high-entropy alloy for cryogenic applications, Science 345 (2014) 1153-1158.

[21] Z. Li, K.G. Pradeep, Y. Deng, D. Raabe, C.C. Tasan, Metastable high-entropy dual-phase alloys overcome the strength-ductility trade-off, Nature 534 (2016) 227-230.

[22] O.N. Senkov, G.B. Wilks, D.B. Miracle, C.P. Chuang, P.K. Liaw, Refractory 584 high-entropy 
alloys, Intermetallics 18 (2010) 1758-1765.

[23] M.H. Chuang, M.H. Tsai, W.R. Wang, S.J. Lin, J. W. Yeh, Microstructure and wear behavior of $\mathrm{Al}_{\mathrm{x}} \mathrm{Co}_{1.5} \mathrm{CrFeNi}_{1.5} \mathrm{Ti}_{\mathrm{y}}$ high-entropy alloys, Acta Mater. 59 (16) (2011) 6308-6317.

[24] Y.F. Kao, S.K. Chen, T.J. Chen, P.C. Chu, J.W. Yeh, S.J. Lin, Electrical, magnetic, and Hall properties of $\mathrm{Al}_{\mathrm{x}} \mathrm{CoCrFeNi}$ high-entropy alloys, J Alloy. Compd. 509 (5) (2011) 1607-1614.

[25] F. Otto, A. Dlouhy, C. Somsen, H. Bei, G. Eggeler, E.P. George, The influences of temperature and microstructure on the tensile properties of a CoCrFeMnNi high-entropy alloy, Acta Mater. 61 (2013) 5743-5755.

[26] S.G. Ma, S.F. Zhang, M.C. Gao, P.K. Liaw, Y. Zhang, A successful synthesis of theCoCrFeNiAl ${ }_{0.3}$ single-crystal, high-entropy alloy by Bridgman solidification, JOM 65 (12) (2013) 1751-1758.

[27]Y. Zou, H. Ma, R. Spolenak, Ultrastrong ductile and stable high-entropy alloys at small scales, Nat. Commun. 6 (2015) 7748.

[28] C.W. Tsai, Y.L. Chen, M.H. Tsai, J.W. Yeh, T.T. Shun, S.K. Chen, Deformation and annealing behaviors of high-entropy alloy $\mathrm{Al}_{0.5} \mathrm{CoCrCuFeNi}$, J Alloy. Compd. 486 (1) (2009) 427-435.

[29] T.T. Shun, Y.C. Du, Microstructure and tensile behaviors of $\mathrm{FCC} \mathrm{Al}_{0.3} \mathrm{CoCrFeNi}_{\text {high entropy }}$ alloy, J Alloy. Compd. 479 (1) (2009) 157-160.

[30] D.Y. Li, Y. Zhang, The ultrahigh Charpy impact toughness of forged $\mathrm{Al}_{\mathrm{x}} \mathrm{CoCrFeNi}$ high entropy alloys at room and cryogenic temperatures, Intermetallics 70 (2016) 24-28.

[31] Z. Tang, M.C. Gao, H.Y. Diao, T.F. Yang, J.P. Liu, T.T. Zuo, Y. Zhang, Z.P. Lu, Y.Q. Cheng, Y.W. Zhang, K.A. Dahmen, P.K. Liaw, T. Egami, Aluminum alloying effects on lattice types, microstructures, and mechanical behavior of high-entropy alloys systems, JOM 65 (12) (2013) $1848-1858$.

[32] S.Q. Xia, X. Yang, T.F. Yang, S. Liu, Y. Zhang, Irradiation Resistance in $\mathrm{Al}_{\mathrm{x}} \mathrm{CoCrFeNi}$ High Entropy Alloys, JOM 67 (10) (2015) 2340-2344.

[33] J.Y. He, W.H. Liu, H. Wang, Y. Wu, X.J. Liu, T.G. Nieh, Z.P. Lu, Effects of Al addition on structural evolution and tensile properties of the FeCoNiCrMn high-entropy alloy system, Acta Mater. 62 (2014) 105-113. 
[34] J.J. Lewandowski, P. Lowhaphandu, Effects of hydrostatic pressure on mechanical behavior and deformation processing of materials, Intl. Mater. Rev. 43 (4) (1998) 145-188.

[35] R.W. Margevicius, J.J. Lewandowski, Deformation texture of hydrostatically extruded polycrystalline NiAl, Scripta Metal. Mater. 29 (12) (1993) 1651-1654.

[36] J.J. Lewandowski, B. Berger, J.D. Rigney, S.N. Patankar, Effects of dislocation substructure on strength and toughness in polycrystalline NiAl processed via low-temperature hydrostatic extrusion, Philos. Mag. A, 78 (3) (1998) 643-656.

[37] E. Aydogan, S. Pal, O. Anderoglu, S.A. Maloy, S.C. Vogel, G.R. Odette, J.J. Lewandowski, D.T. Hoelzer, I.E. Anderson, J.R. Rieken, Effect of tube processing methods on the texture and grain boundary characteristics of 14YWT nanostructured ferritic alloys, Mater. Sci. Eng. A 661 (2016) $222-232$.

[38] G. Laplanche, O. Horst, F. Otto, G. Eggeler, E.P. George, Microstructural evolution of a CoCrFeMnNi high-entropy alloy after swaging and annealing, J Alloy. Compd. 647 (2015) $548-557$.

[39] P.P. Bhattacharjee, G.D. Sathiaraj, M. Zaid, J.R. Gatti, C. Lee, C.W. Tsai, J.W. Yeh, Microstructure and texture evolution during annealing of equiatomic CoCrFeMnNi high-entropy alloy, $\mathrm{J}$ Alloy Compd. 587 (2014) 544-552.

[40] F.J. Wang, Y. Zhang, G.L. Chen, H.A. Davies, Cooling rate and size effect on the microstructure and mechanical properties of AlCoCrFeNi high entropy alloy. J Eng. Mater. Tech. 131 (3) (2009) 034501.

[41] C.J. Tong, Y.L. Chen, J.W. Yeh, S.J. Lin, S.K. Chen, T.T. Shun, C.H. Tsau, S.Y. Chang, Microstructure characterization of $\mathrm{Al}_{\mathrm{x}} \mathrm{CoCrCuFeNi}$ high-entropy alloy system with multiprincipal elements. Metal. Mater. Trans. A 36 (4) (2005) 881-893.

[42] C.P. Lee, C.C. Chang, Y.Y. Chen, J.W. Yeh, H.C. Shih, Effect of the aluminum content of $\mathrm{Al}_{\mathrm{x}} \mathrm{CrFe}_{1.5} \mathrm{MnNi}_{0.5}$ high-entropy alloys on the corrosion behavior in aqueous environments, Corros. Sci. 50 (7) (2008) 2053-2060.

[43] H.Y. Yasuda, K. Shigeno, T. Nagase, Dynamic strain aging of $\mathrm{Al}_{0.3} \mathrm{CoCrFeNi}$ high entropy alloy single crystals, Scripta Mater. 108 (2015) 80-83. 
[44] Y. Deng, C.C. Tasan, K.G. Pradeep, H. Springer, A. Kostka, D. Raabe, Design of a twinning-induced plasticity high entropy alloy, Acta Mater. 94 (2015) 124-133.

[45] G. Sha, K. Tugcu, X.Z. Liao, P.W. Trimby, M.Y. Murashkin, R.Z. Valiev, S.P. Ringer, Strength, grain refinement and solute nanostructures of an $\mathrm{Al}-\mathrm{Mg}-\mathrm{Si}$ alloy (AA6060) processed by high-pressure torsion, Acta Mater. 63 (2014) 169-179.

[46] S. Mandal, K.G. Pradeep, S. Zaefferer, D. Raabe, A novel approach to measure grain boundary segregation in bulk polycrystalline materials in dependence of the boundaries five rotational degrees of freedom, Scripta Mater. 81 (2014) 16-19.

[47] G. Sha, R.K.W. Marceau, X. Gao, B.C. Muddle, S.P. Ringer, Nanostructure of aluminum alloy 2024: segregation, clustering and precipitation processes, Acta Mater. 59 (4) (2011) 1659-1670.

[48] K.G. Pradeep, N. Wanderka, P. Choi, J. Banhart, B. S. Murty, D. Raabe, Atomic-scale compositional characterization of a nanocrystalline $\mathrm{AlCrCuFeNiZn} \mathrm{high-entropy} \mathrm{alloy} \mathrm{using} \mathrm{atom}$ probe tomography, Acta Mater. 61 (12) (2013) 4696-4706.

[49] N. Park, X. Li, N. Tsuji, Microstructure and Mechanical Properties of $\mathrm{Co}_{21} \mathrm{Cr}_{22} \mathrm{Cu}_{22} \mathrm{Fe}_{21} \mathrm{Ni}_{14}$ Processed by High Pressure Torsion and Annealing, JOM 67 (10) (2015) 2303-2309.

[50] Q.H. Tang, Y. Huang, Y.Y. Huang, X.Z. Liao, T.G. Langdon, P.Q. Dai, Hardening of an $\mathrm{Al}_{0.3} \mathrm{CoCrFeNi}$ high entropy alloy via high-pressure torsion and thermal annealing, Mater. Lett. $151(2015)$ 126-129.

[51] W.R. Wang, W.L. Wang, S.C. Wang, Y.C. Tsai, C.H. Lai, J.W. Yeh, Effects of Al addition on the microstructure and mechanical property of $\mathrm{Al}_{\mathrm{x}} \mathrm{CoCrFeNi}$ high-entropy alloys, Intermetallics 26 (2012) 44-51.

[52] R.D. Noebe, R.R. Bowman, M.V. Nathal, Physical and mechanical properties of the B2 compound NiAl. Int. Mater. Rev. 38 (4) (1993) 193-232.

[53] D.B. Miracle. The physical and mechanical properties of NiAl. Acta Metall. Mater. 41 (3) (1993) 649-684.

[54] W.R. Wang, W.L. Wang, J.W. Yeh, Phases, microstructure and mechanical properties of $\mathrm{Al}_{\mathrm{x}} \mathrm{CoCrFeNi}$ high-entropy alloys at elevated temperatures, J Alloy. Compd. 589 (2014) 143-152.

[55] M.C. Gao, D.E. Alman, Searching for next single-phase high-entropy alloy compositions. Entropy, 
15 (10) (2013) 4504-4519.

[56] R. Feng, M.C. Gao, C. Lee, M. Mathes, T. Zuo, S. Chen, J.A. Hawk, Y. Zhang, P.K. Liaw, Design of Light-Weight High-Entropy Alloys, Entropy 18 (9) (2016) 333.

[57] E. Orowan, Dislocations in metals, AIME, New York, (1954) 131.

[58] D.L. Holt, Dislocation cell formation in metals, J Appl. Phys. 41 (1970) 3197-3201.

[59] W.H. Liu, Y. Wu, J.Y. He, T.G. Nieh, Z.P. Lu, Grain growth and the Hall-Petch relationship in a high-entropy FeCrNiCoMn alloy, Scripta Mater. 68 (7) (2013) 526-529.

[60] J.Y. He, H. Wang, H.L. Huang, X.D. Xu, M.W. Chen, Y. Wu, X.J. Liu, T.G. Nieh, K. An, Z.P. Lu, A precipitation-hardened high-entropy alloy with outstanding tensile properties, Acta Mater. 102 (2016) 187-196.

[61] S.Y. Chen, X. Xie, B.L. Chen, J.W. Qiao, Y. Zhang, Y. Ren, K.A. Dahmen, P.K. Liaw, Effects of Temperature on Serrated Flows of $\mathrm{Al}_{0.5} \mathrm{CoCrCuFeNi}$ High-Entropy Alloy, JOM, 67 (10) (2015) $2314-2320$

[62] J. Joseph, T. Jarvis, X. Wu, N. Stanford, P. Hodgson, D.M. Fabijanic, Comparative study of the microstructures and mechanical properties of direct laser fabricated and arc-melted $\mathrm{Al}_{\mathrm{x}} \mathrm{CoCrFeNi}$ high entropy alloys, Mater. Sci. Eng. A, 633 (2015) 184-193. 
Figures

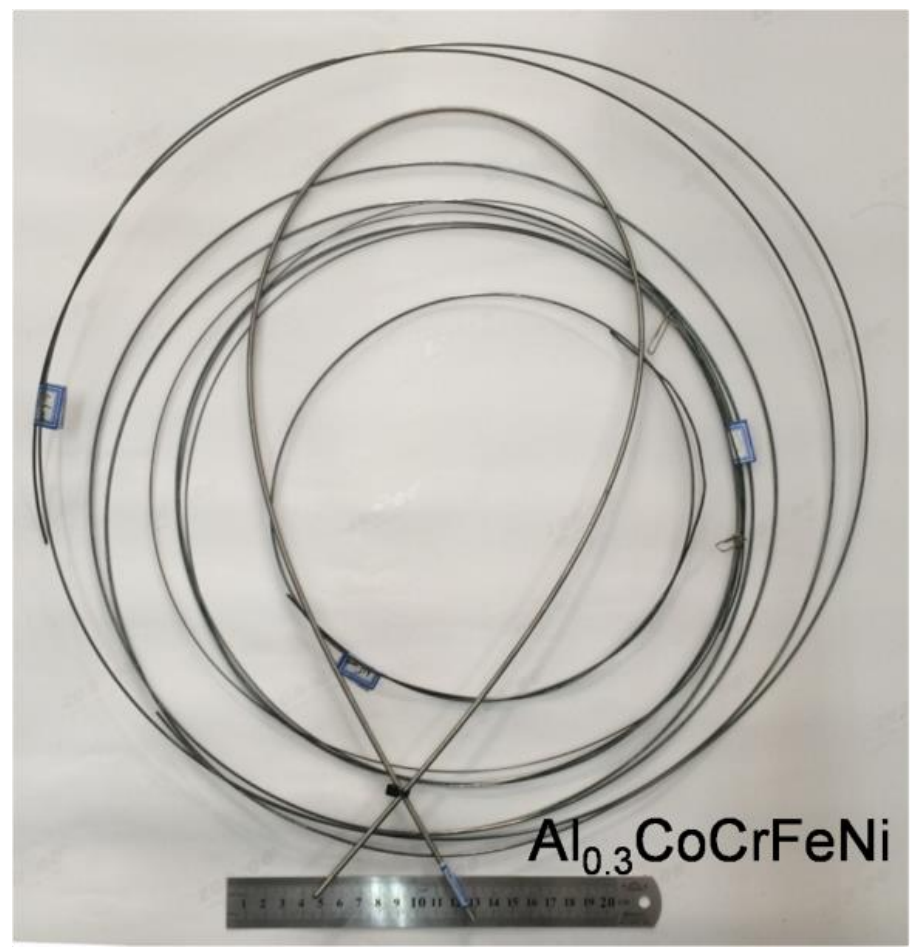

Fig. 1 Macroscopic views of hot-drawn smooth $\mathrm{Al}_{0.3} \mathrm{CoCrFeNi}$ fibers. Fiber diameters range from 1.00 to $3.15 \mathrm{~mm}$. 


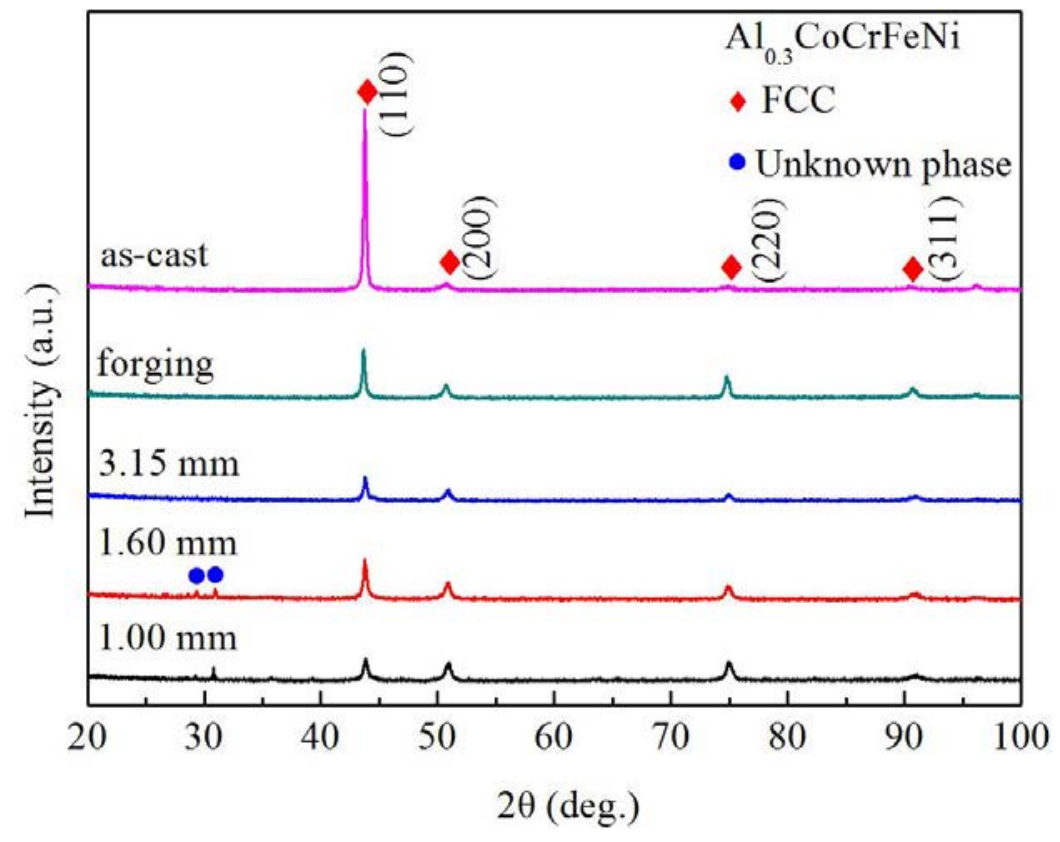

Fig. $2 \mathrm{XRD}$ patterns from the as-cast $\mathrm{Al}_{0.3} \mathrm{CoCrFeNi} \mathrm{HEA}$ material as well as after various deformation sequences to produce fibers. All samples were predominantly FCC according to the XRD results. 


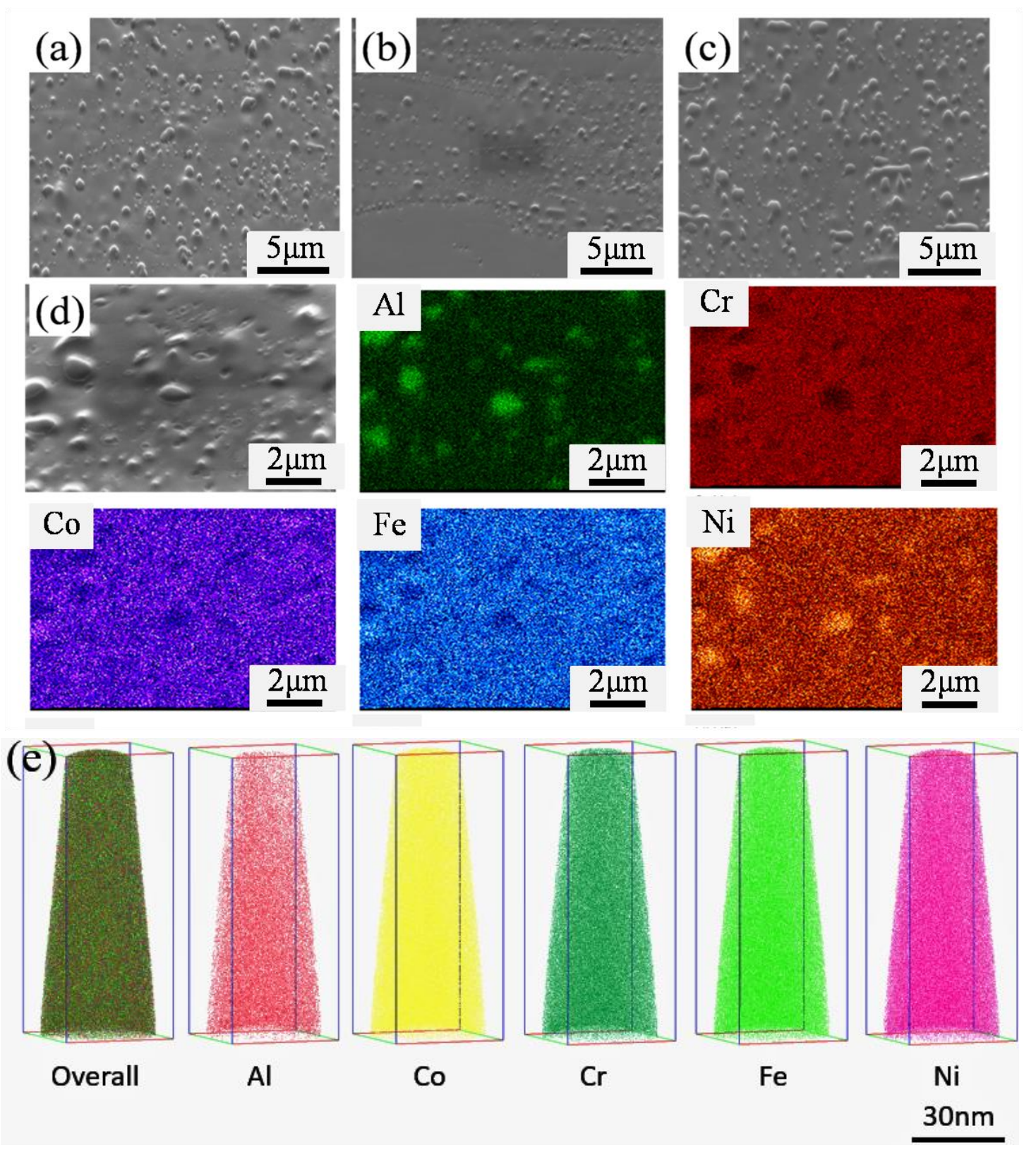

Fig. 3 SEM images of the microstructures of the longitudinal sections of the $\mathrm{Al}_{0.3} \mathrm{CoCrFeNi}$ fibers with diameters of: (a) $3.15 \mathrm{~mm}$, (b) $1.60 \mathrm{~mm}$, and (c) $1.00 \mathrm{~mm}$, (d) Energy-dispersive spectroscopy of the $1.00 \mathrm{~mm}$ diameter fibers, and (e) APT elemental maps displaying the $1.00 \mathrm{~mm}$ diameter fibers' atomic positions of the $\mathrm{Al}$, 
$\mathrm{Co}, \mathrm{Cr}, \mathrm{Fe}$, and $\mathrm{Ni}$ of the matrix.
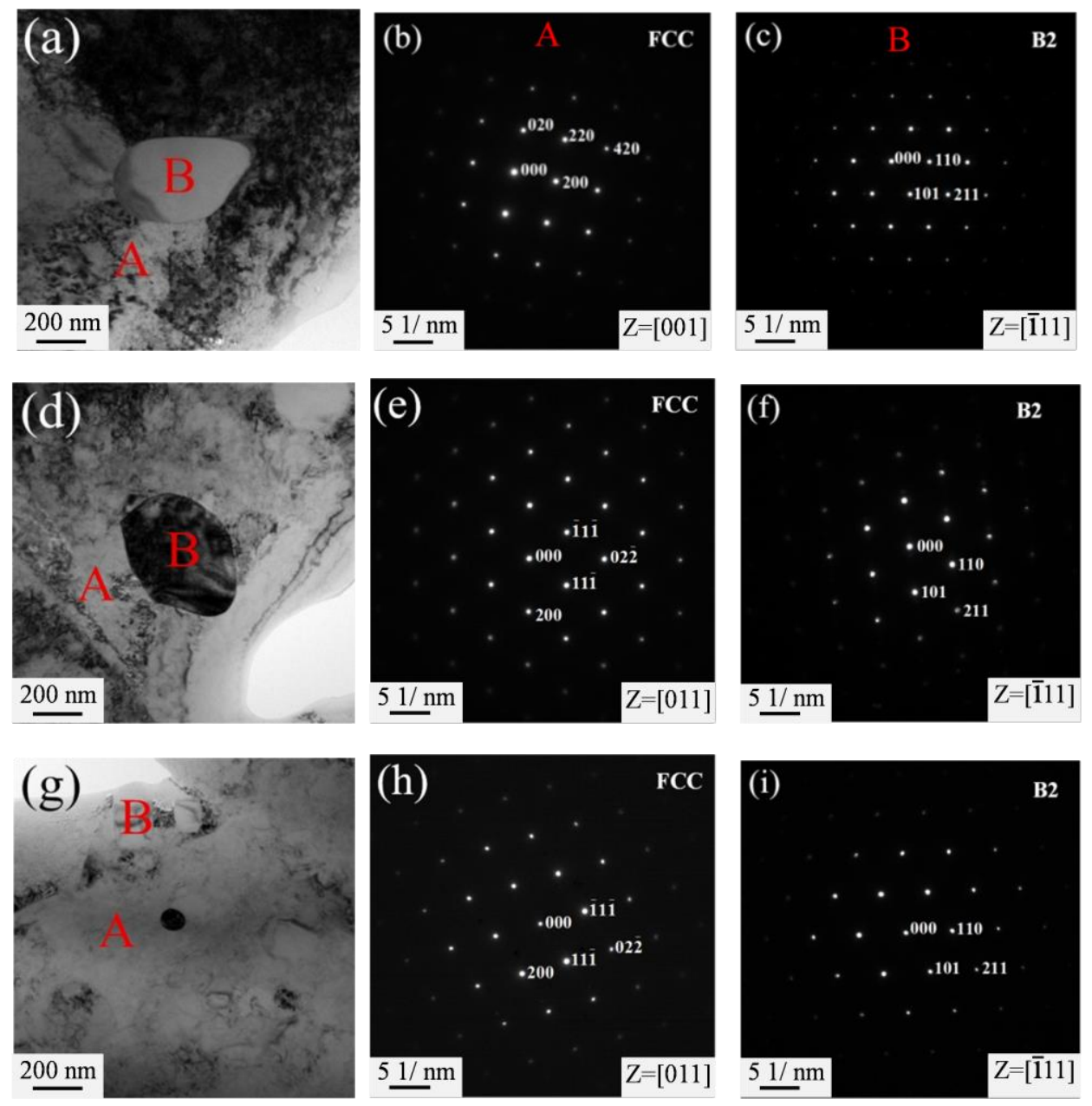

Fig. 4 TEM of the (a) 3.15 , (b) 1.60 , and (c) $1.00 \mathrm{~mm} \mathrm{Al}{ }_{0.3} \mathrm{CoCrFeNi}$ fibers and the selected area diffraction patterns (SADP) for each $(b, c),(e, f)$, and $(h, i)$, respectively. The matrix (A) and precipitate particles (B) are identified for the TEM (a, d, g) and SADP in (b, e, h) and (c, f, i), respectively. 

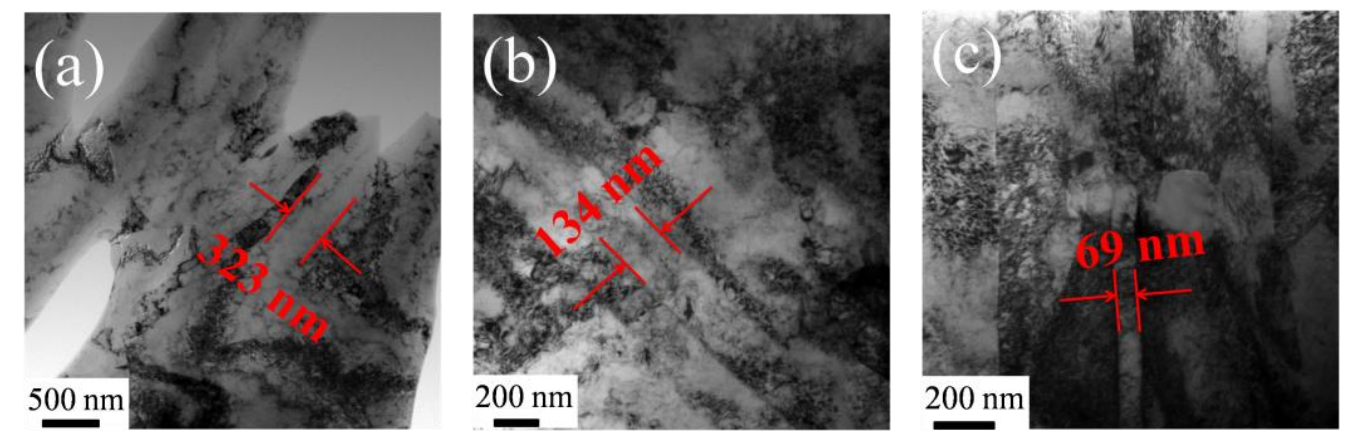

Fig. 5 TEM micrographs of the $\mathrm{Al}_{0.3} \mathrm{CoCrFeNi}$ fibers: (a) $3.15 \mathrm{~mm}$, (b) $1.60 \mathrm{~mm}$, (c) $1.00 \mathrm{~mm}$, showing high dislocation density. 

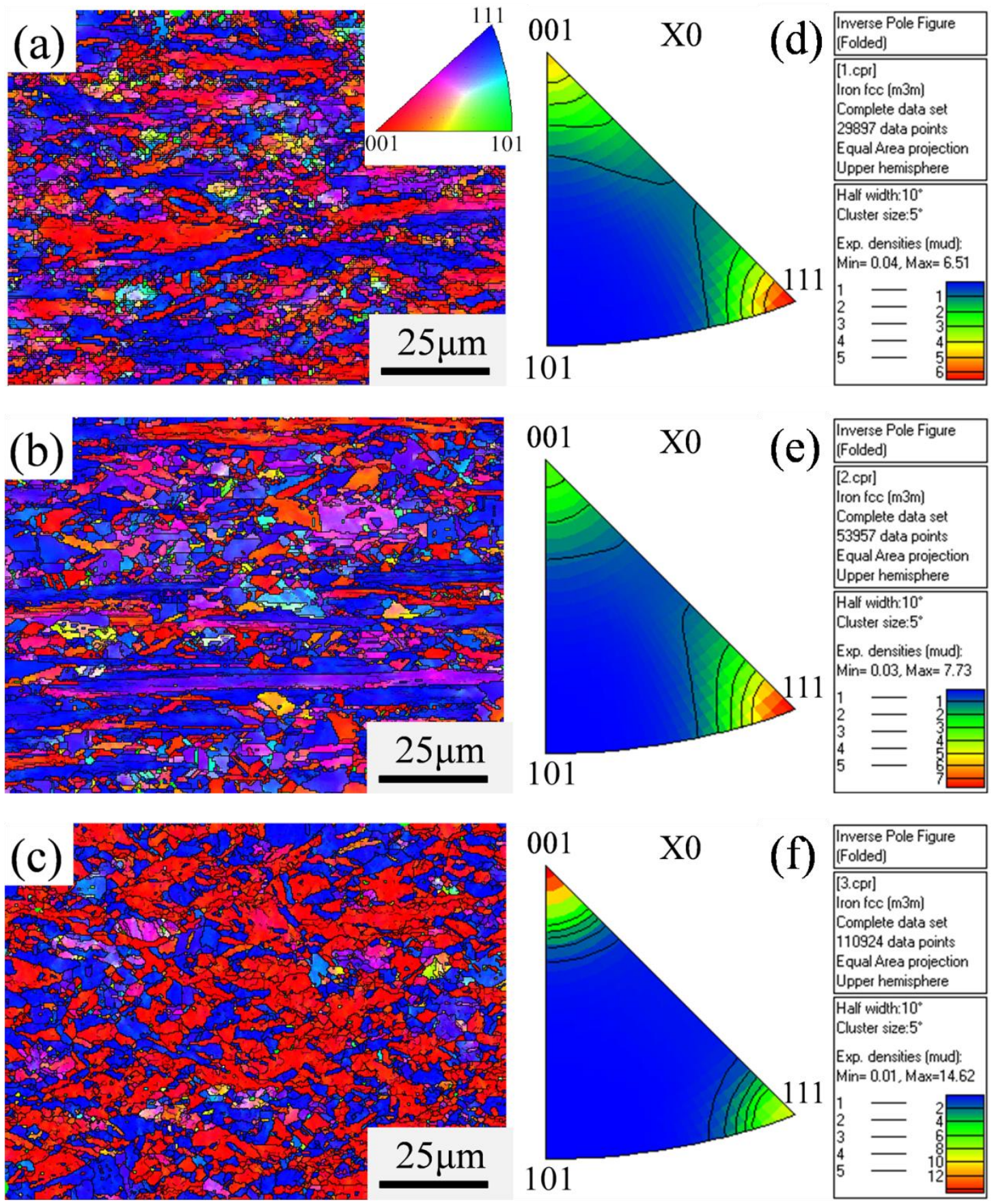

Fig. 6 EBSD images and texture evolution of $\mathrm{Al}_{0.3} \mathrm{CoCrFeNi}$ fibers with different diameters. Figures $6(\mathrm{a}) 3.15 \mathrm{~mm}, 6(\mathrm{~b}) 1.60 \mathrm{~mm}$, and $6(\mathrm{c}) 1.00 \mathrm{~mm}$ are color-coded grain orientation maps where the colors indicate the crystal orientations parallel to the 6/ 11 
deformation direction displayed in the stereographic triangle [top right of (a)]. Figures 6(d), 6(e) and 6(f) are the longitudinal section crystallographic orientations for fibers with diameters of $3.15 \mathrm{~mm}, 1.60 \mathrm{~mm}$ and $1.00 \mathrm{~mm}$. The IPFs highlight the texture corresponding to the deformation direction. The scale of the IPFs is shown at the right, and the maximum pole density of each IPF is designated with red color.

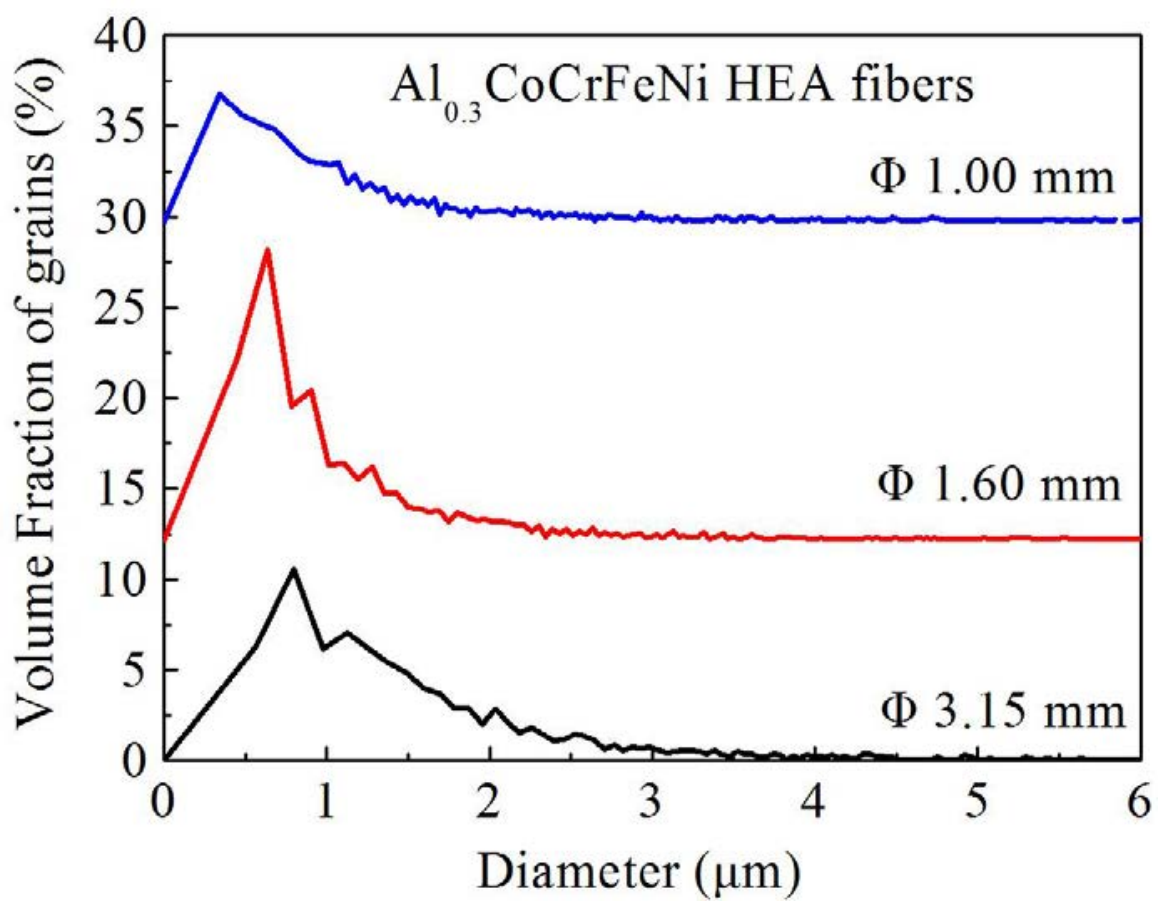

Fig. 7 Statistical volume distributions of grain sizes for the different diameters of $\mathrm{Al}_{0.3} \mathrm{CoCrFeNi}$ fibers. 

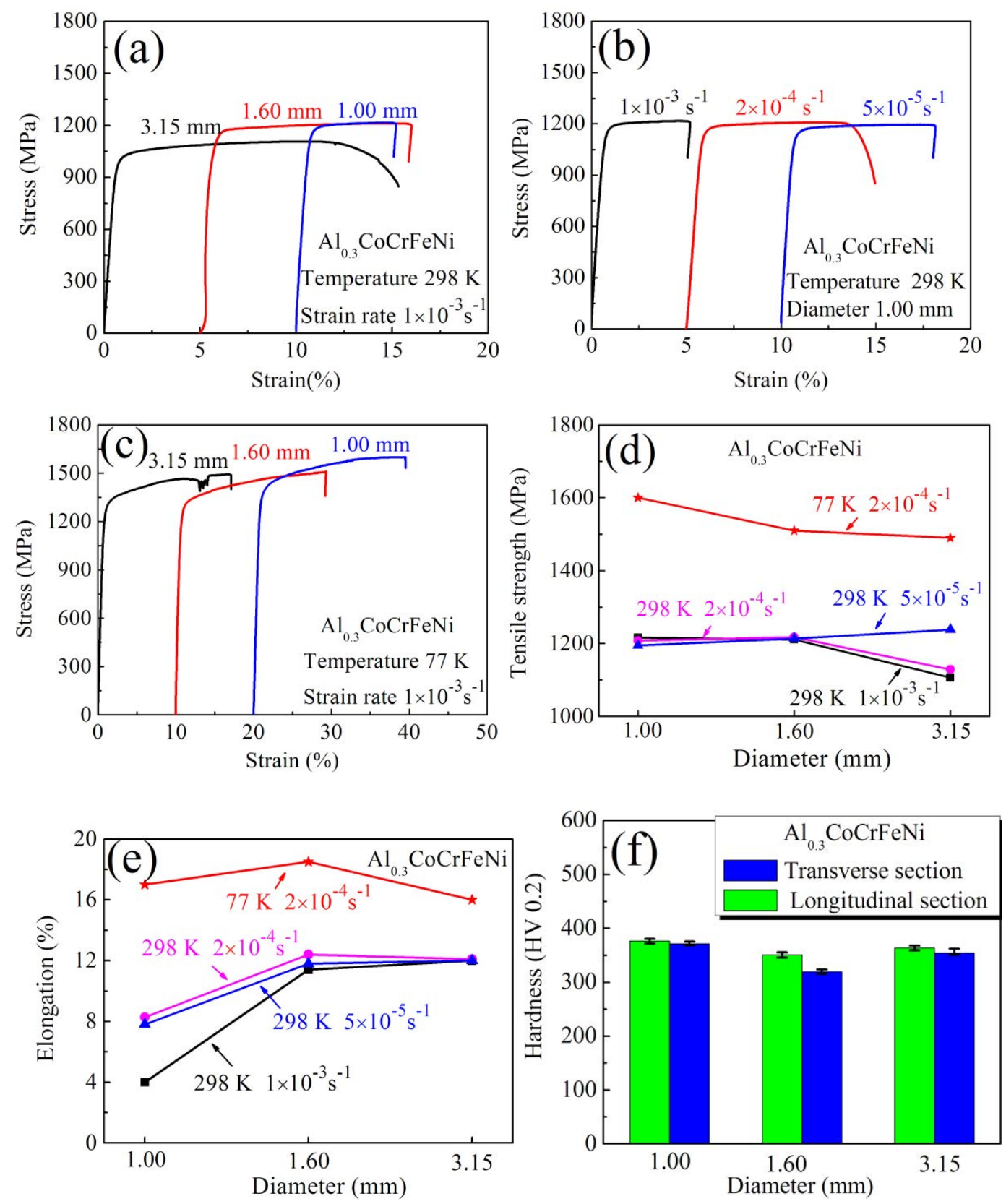

Fig. 8 Mechanical properties of the $\mathrm{Al}_{0.3} \mathrm{CoCrFeNi}$ fibers: (a) and (b) engineering stress-strain curves with different diameters and strain rates at room temperature, respectively; (c) engineering stress-strain curves at $77 \mathrm{~K}$; (d) and (e) tensile strength and elongation as a function of diameter, respectively; and (f) Vickers hardness variation with change in diameter and section (i.e., longitudinal vs. transverse). 

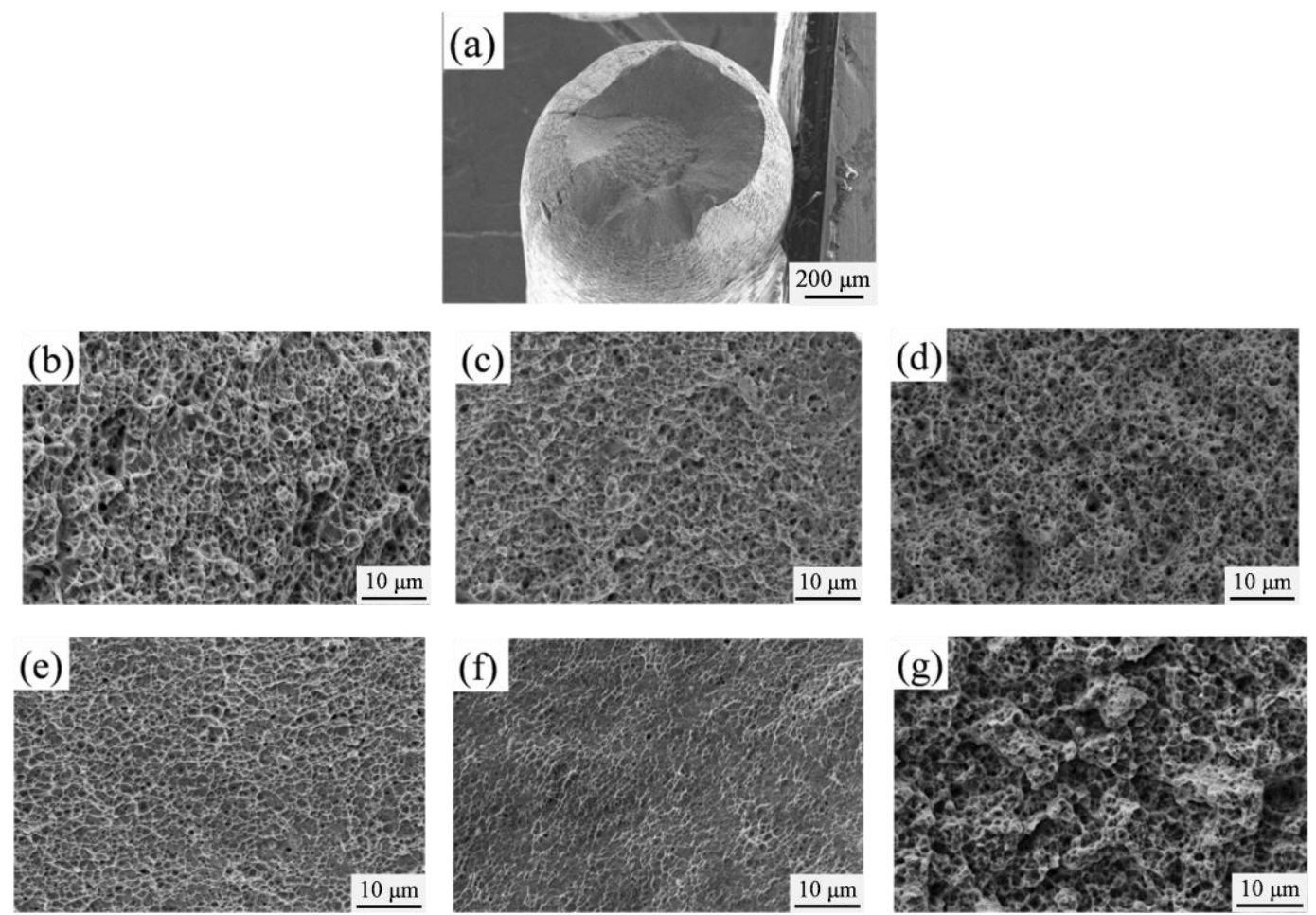

Fig. 9 (a) SEM image of the $\mathrm{Al}_{0.3} \mathrm{CoCrFeNi}$ fiber fracture surface showing necking; (b), (c), and (d) presenting SEM images of the dimpled fracture surfaces in the 1.00 $\mathrm{mm}$ diameter fiber tested at strain rates of $1 \times 10^{-3} \mathrm{~s}^{-1}, 2 \times 10^{-4} \mathrm{~s}^{-1}$, and $5 \times 10^{-5} \mathrm{~s}^{-1}$, respectively; (e), (f), and (g) showing SEM images of the dimpled fracture surfaces in the tensile samples with diameters of $3.15 \mathrm{~mm}, 1.60 \mathrm{~mm}$, and $1.00 \mathrm{~mm}$, respectively, at a strain rate of $2 \times 10^{-4} \mathrm{~s}^{-1}$ at $77 \mathrm{~K}$. 

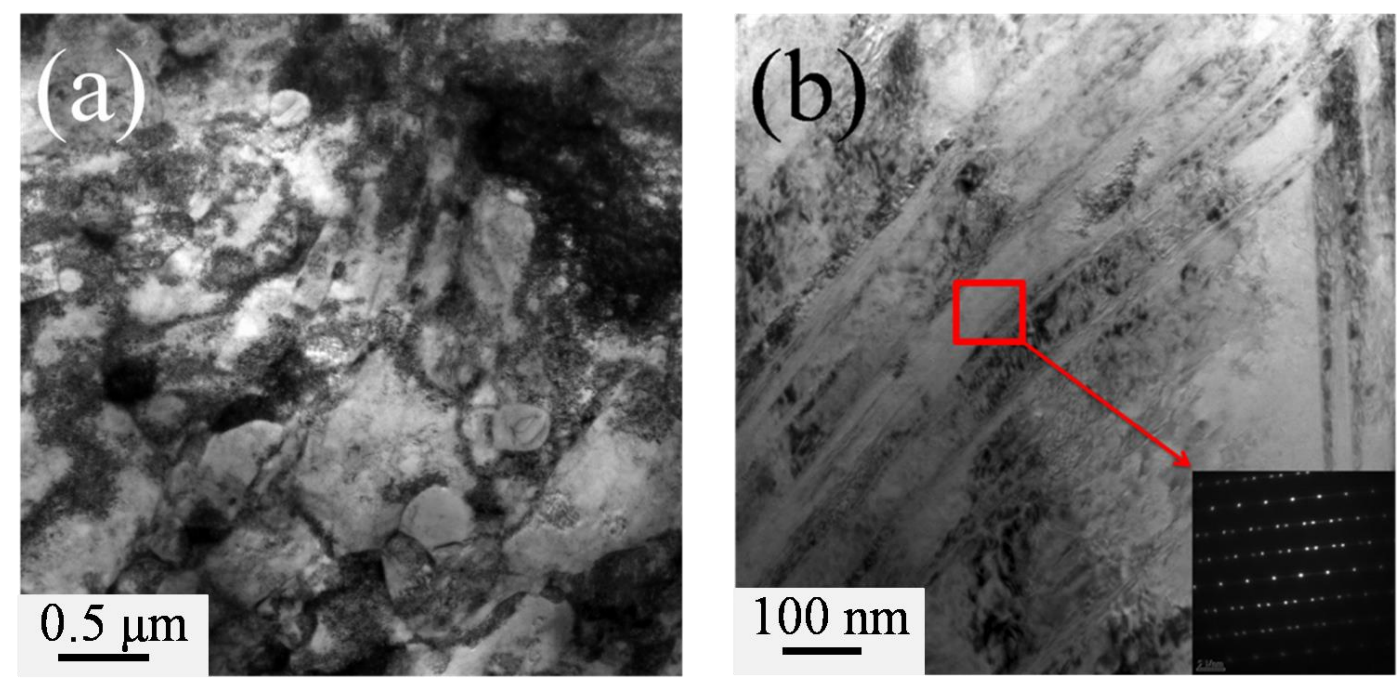

Fig. 10 TEM micrographs taken from the $3.15 \mathrm{~mm}$ diameter $\mathrm{Al}_{0.3} \mathrm{CoCrFeNi}$ fibers tested at:(a) $298 \mathrm{~K}$, (b) $77 \mathrm{~K}$. 


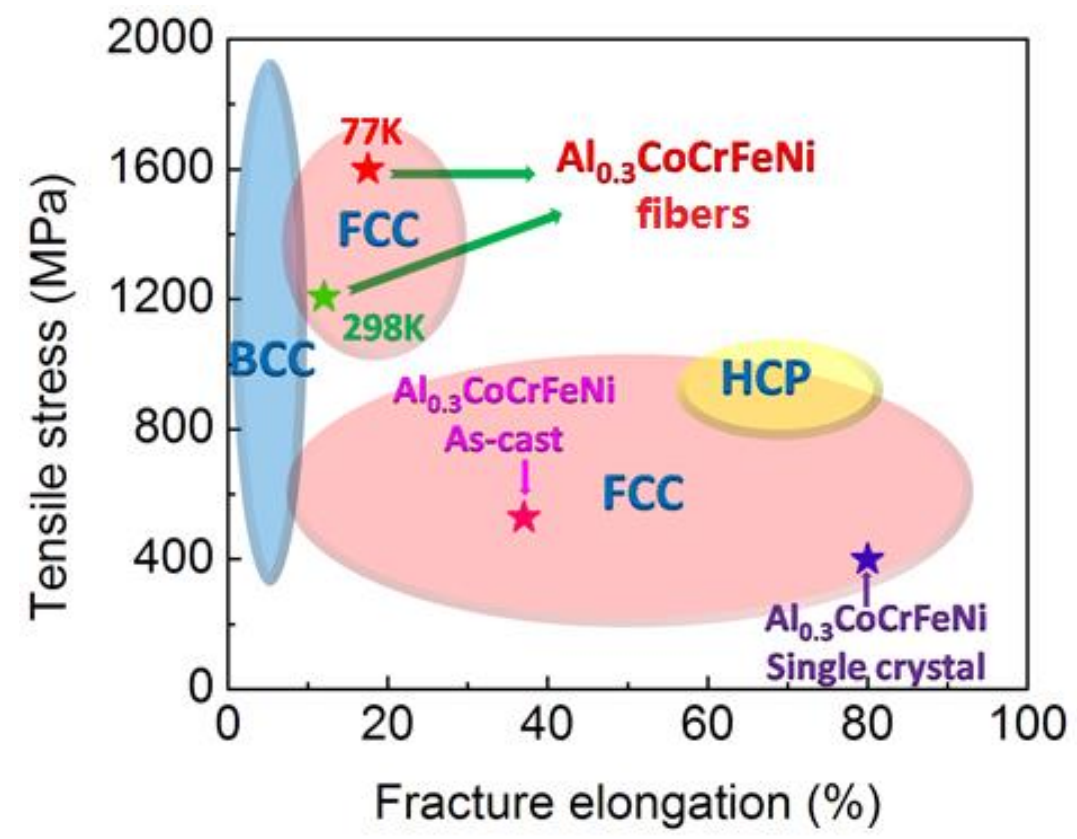

Fig. 11 The map of tensile strength and ductility combinations of various phases of high entropy alloys. 
Tables

Table 1. Compositions of the $\mathrm{Al}_{0.3} \mathrm{CoCrFeNi} \mathrm{HEA}$ fibers

\begin{tabular}{llccccc}
\hline Atomic \% & & Al & Co & Cr & Fe & Ni \\
\hline Nominal & & 6.98 & 23.26 & 23.26 & 23.26 & 23.26 \\
\hline $\mathbf{3 . 1 5} \mathbf{~ m m}$ & A (matrix) & 5.18 & 22.86 & 25.02 & 24.03 & 22.87 \\
& B (particle) & 28.16 & 3.79 & 9.55 & 16.09 & 42.40 \\
\hline $\mathbf{1 . 6 0} \mathbf{~ m m}$ & A (matrix) & 3.22 & 23.33 & 24.90 & 23.64 & 26.37 \\
& B (particle) & 29.70 & 13.77 & 4.83 & 10.72 & 49.39 \\
\hline $\mathbf{1 . 0 0} \mathbf{~ m m}$ & A (matrix) & 3.99 & 24.46 & 24.09 & 24.44 & 23.00 \\
& B (particle) & 22.99 & 16.43 & 4.45 & 11.13 & 44.97 \\
\hline
\end{tabular}

Table 2. Properties and microstructure summary of the $\mathrm{Al}_{0.3} \mathrm{CoCrFeNi}$

HEA fabricated by various methods

\begin{tabular}{cccccc}
\hline & $\boldsymbol{\sigma}_{\mathbf{y}}(\mathbf{M P a})$ & $\boldsymbol{\sigma}_{\mathbf{u}}(\mathbf{M P a})$ & $\boldsymbol{\varepsilon}_{\mathbf{u}}(\mathbf{\%})$ & $\mathbf{d}(\boldsymbol{\mu m})$ & Ref. \\
\hline Hot-drawn fibers $(298 \mathrm{~K})$ & 1,147 & 1,207 & 12 & 1.6 & The present work \\
Hot-drawn fibers $(77 \mathrm{~K})$ & 1,320 & 1,600 & 17.5 & 1.6 & The present work \\
As-cast & 275 & 528 & 37 & 50 & Error! \\
Single-crystal & 185 & 399 & 80 & 3,000 & Bookmark not \\
Direct laser fabricated & 200 & - & - & - & defined. \\
& & & & & Error! \\
& & & & & Bookmark not \\
& & & & & 47 \\
\hline
\end{tabular}




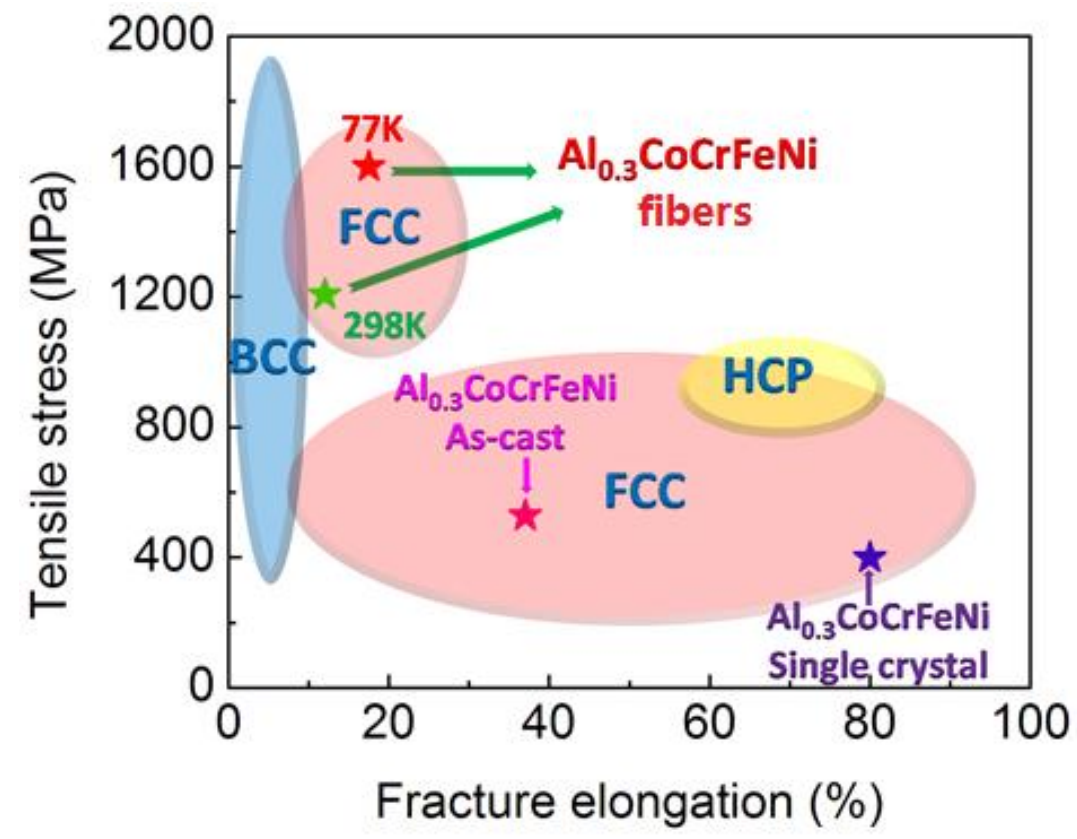

The map of tensile strength and ductility combinations of various phases of high entropy alloys. 